\title{
POLÍTICAS PÚBLICAS E TEORIAS DO ESTADO: O PAPEL DAS TEORIAS DE MÉDIO ALCANCE
}

\section{PUBLIC POLICIES AND STATE THEORIES: THE ROLE OF MIDDLE RANGE THEORIES}

IVAN CÉSAR RIBEIRO

Resumo: O exame da ação do Estado, tanto sob a ótica das Políticas Públicas quanto nas tradições mais antigas do estudo das teorias do Estado, sofreu durante muito tempo a influência das tentativas do desenvolvimento das chamadas grandes teorias. Este artigo discute essa evolução e examina desdobramentos recentes, com a ampliação da influência das teorias de médio alcance e o desenvolvimento de uma abordagem de Direito e Políticas Públicas.

Palavras-Chave: Direito e Políticas Públicas; Teorias de Médio Alcance; Ação do Estado.

ABSTRACT: The study of the state action, either under the perspective of the public policies field or in the old tradition of state theories, was for a long time under the influence of the attempts of creating the so-called grand theories. This article discusses this evolution and examines its recent unfold, foremost to point the increasing influence of middle-range theories and the development of a law and public policy approach.

KeYwORDS: Law and Public Policy, Middle-Range Theories, State theories.

\footnotetext{
${ }^{1}$ Professor de Direito e Políticas Públicas da Universidade Federal de São Paulo (Unifesp) Coordenador e Pesquisador-chefe do Centro de Estudos da Ordem Econômica - CEOE/Unifesp e da Tndnet - Rede Mundial de pesquisadores em Direito e Políticas Públicas. Email: iribeiro@unifesp.br, Orcid: https://orcid.org/0000-0003-4706-7408, Lattes: http://lattes.cnpq.br/1537678142289537.
} 


\section{INTRODUÇÃO}

PETER WAGNER, teórico com produção em história das ciências sociais, relaciona a emergência do conhecimento social e das formas de intervenção através de políticas públicas às diferentes formas de superação das limitações do conceito liberal de sociedade. Na França a falha da Revolução de 1848 teria mostrado que somente o Estado Democrático não seria suficiente para resolver a questão da organização social. Na Itália e Alemanha, os processos de unificação no período entre 1861 e 1871 mudaram profundamente os termos do debate político e a orientação dos cientistas sociais nos dois países (WAGNER, 2007, p. 32). A ideia de melhora da sociedade parecia, nestes dois casos, ligada ao conceito de Estado nacional.

De forma geral, a construção de políticas sociais nacionais, onde sobressaía a importância do Estado, era defendida em todo o continente europeu ao final do século XIX. Cruzando o Atlântico, pesquisadores sociais nos Estados Unidos tendiam a ser relutantes em atribuir essa preponderância ao Estado, superior aos indivíduos, já que um estado central forte ainda não existia no país (WAGNER, 2007, p. 32-33). O autor reconhece o liberalismo individualista como a tradição maior entre pesquisadores e reformadores sociais americanos, tornando populares abordagens calcadas no comportamento individual como as emergentes Psicologia e Psicologia Social.

CelinA SOUZA desenvolve raciocínio semelhante, ao sugerir o nascimento das Políticas Públicas, como disciplina acadêmica, nos Estados Unidos (SOUZA, 2007, p. 66-67). O país teria seguido uma tradição diferente das nações europeias, onde os estudos se concentravam nas análises do Estado e suas instituições. Na linha do que também sugere WAGNER (2007, p. 32) em relação aos pensadores franceses, alemães e italianos, para a pesquisadora os doutrinadores europeus chegariam às políticas públicas através das discussões sobre as teorias explicativas do Estado, enquanto nos Estados Unidos a ênfase se daria diretamente sobre a ação dos governos, endereçando as preocupações com as teorias do Estado apenas de forma indireta.

Nos vários países e épocas pode-se localizar uma profunda relação entre a concepção de Estado preponderante e as políticas implementadas pelos governos. Essa influência aparece na consecução de políticas sociais e entre aquelas que apenas mediatamente encontram fundamentos nos direitos sociais, como as políticas industriais, de crédito, externa e outras. Assim, o resultado dessas políticas decorre da conjugação de muitos fatores, com influência decisiva das teorias do Estado.

Essa relação se dá, como se vê, em um plano bastante amplo. O contexto é o das chamadas Grandes Teorias, um conceito surgido do debate iniciado entre Talcott Parsons e Robert Merton a partir de fins da década de 40 (PARSONS, 1948; MERTON, 1948). A ideia de uma teoria capaz de explicar qualquer fenômeno de forma 
completa e definitiva enfrenta problemas quando descemos ao nível da definição, implementação e acompanhamento das políticas públicas e suas relações com o Estado, algo que se constata também em outras áreas das ciências sociais como a Sociologia e a Teoria do Estado².

De fato, o Direito têm papel fundamental neste olhar sobre a microestrutura das políticas públicas. O processo do desenho dessas políticas, deslindando questões de competência, participação dos atores sociais, formas de cooperação federativa e outros, assenta-se em mecanismos jurídicos. A definição das formas de financiamento e dos beneficiários das políticas resolve, através também de mecanismos jurídicos, questões redistributivas e de equidade importantes. Olhados os artigos deste dossiê, percebemos que o Direito é o tijolo fundamental na construção das políticas - essas questões serão examinadas mais à frente.

Acompanhando essa característica do Direito como building block das políticas públicas, uma abordagem positiva, voltada ao entendimento com base científica dos incentivos, restrições, pressupostos, relações de causalidade e outros componentes, necessita da construção de uma linguagem comum e do exame empírico dos efeitos desses mesmos mecanismos jurídicos sobre resultados, partindo-se de hipóteses testáveis. Ou seja, como prega M. P. BuCCI, o exame das políticas públicas requer o "estabelecimento de referências comuns e procedimentos de pesquisa generalizáveis" (BUCCI, neste dossiê). Para tanto, requer-se a construção de uma abordagem de Direito e Políticas Públicas, para além do tradicional campo de Políticas Públicas e a consideração das chamadas Teorias de Médio Alcance.

Para defender essas proposições, este artigo inicia examinando as concepções marxistas e neoliberal de políticas públicas, incluindo a crítica dos defensores do Estado de Bem Estar Social (seções II e III). A seção IV apresenta um breve histórico das discussões sobre as Teorias de Médio Alcance, iniciando com o clássico debate entre Parsons e Merton e seus desdobramentos, inclusive nos campos da Teoria do Estado e da Sociologia no Brasil. O possível esgotamento dessas grandes teorias como ferramenta de análise das Políticas Públicas, com exemplos da aplicação das MRTs à abordagem Direito e Políticas Públicas, é examinado na seção V, seguida das conclusões na seção VI.

\section{Políticas Na Análise MarXista}

O Estado, nas análises marxistas, têm um caráter de classe, assim as ações do Estado poderiam ser explicadas através da estrutura da sociedade capitalista, da

\footnotetext{
2 Este desafio é encontrado em alguma medida nos debates sobre as Teorias do Estado (BUCCI, 2018, p. 68-71) e mesmo no Brasil, por exemplo na transição que Florestan Fernandes faz de recortes temáticos mais específicos para as proposições de alcance mais amplo de sua obra A Revolução Burguesa no Brasil (MARTINS, 2006, p. 12-15). Agradeço a Maria Paula Dallari Bucci por comentário neste sentido durante as várias sessões de nosso Grupo "Estado, Direito e Políticas Públicas", durante 2018 e 2019.
} 
ação direta e da articulação dos donos do capital. Para EROS GRAU, neste contexto o direito tem a função de garantir a fluidez das relações de mercado e, diante da característica instável do sistema capitalista, garantir a sua sobrevivência (GRAU, 2010, Capítulo 1). Para o autor, o Estado, assumindo a função de administrar as crises nos processos de mercado, lança mão do Direito como instrumento voltado para sua preservação. Neste momento é que se posta, em sua visão, a implementação de políticas públicas (GRAU, 2010, p. 72)3.

O Estado, segundo as mais variadas correntes marxistas, acaba por agir no interesse da burguesia. A origem dessa hegemonia pode ser econômica, cultural, pode vir das características comuns entre as elites burocráticas e a burguesia, sendo portanto várias as explicações para seu domínio. Ao final, com base nesta influência, a classe capitalista exerce poder sobre o aparato estatal, subordinando a população. Para DOMHOFF esse domínio, entre outros meios, é alcançado através do processo de formação de políticas públicas, especialmente nas chamadas grandes questões como a política externa, fiscal, ambiental e direito sociais (DOMHOFF, 1979, p. 59).

As políticas públicas, em especial as prestações positivas do Estado feitas na forma de serviços públicos como a educação e saúde, são estabelecidas no interesse do capital. OfFE sugere que as estruturas estatais são dotadas de seletividade, implementando as ações diretamente associadas à criação e recriação das condições de acumulação do capital e ao processo de legitimação da dominação de classe (OFFE, 1975; LENHARDT; OFFE, 1984).

Para o autor, o Estado atua como regulador a serviço da manutenção das relações capitalistas em seu conjunto, e a política social é a forma pela qual tenta resolver a transformação duradoura de trabalho não assalariado em trabalho assalariado. As políticas públicas cuidariam não só de qualificar permanentemente a mão de obra para o mercado, mas também de manter o controle sobre as porções da população não inseridas no processo produtivo. De forma resumida, políticas de saúde, educação e outras visam facilitar o processo de acumulação capitalista (OFFE, 1975; LENHARDT; OFFE, 1984, p. 92ss).

O refluxo das políticas sociais, localizado na chamada Crise do Estado de Bem Estar Social dos anos 70, também se faz em favor do capital, fenômeno notado por BERCOVICI e MASSONETTO (2006). Avanços de tecnologia da informação e de organização do trabalho, entre outros fatores, reduzem a importância da mão de

\footnotetext{
${ }^{3}$ Eros Grau discorre mais longamente sobre políticas públicas em seu Direito Posto e Direito Pressuposto (2011, p. 26-32). Sua proposição é a de que o Direito é uma das formas de intervenção na economia, uma das técnicas específicas de atuação, em conjunto com técnicas de absorção, participação, direção e de indução. A passagem de um 'government by laws' para um 'government by policies', conceito desenvolvido por COMPARATO (1998) com base em LOEWENSTEIN (1965) faz com que as políticas públicas, e não mais apenas o Direito, sirvam como instrumento de dominação da burguesia. O desenvolvimento que o autor faz do conceito de políticas públicas, e de suas interações com o Direito, é modesto, não sendo uma de suas grandes linhas de pesquisa.
} 
obra no processo de acumulação capitalista. A financeirização da economia, que pode ser entendida como a hegemonia de uma parcela do capital sobre as outras, no sentido da hegemonia dado por POULANTZAS (1978), muda a função das políticas públicas.

O processo de acumulação passa a ser feito através da apropriação direta do fundo público, usado para garantir o retorno do capital através do pagamento de juros, da constituição de garantias, da cessão de bens públicos materiais e imateriais (BERCOVICI; MASSONETTO, 2006). Veja-se, a respeito, a discussão sobre o Estado Empreendedor de MAZZUCATO (2015), onde o risco das grandes inovações tecnológicas têm ficado, pelo mundo afora, com o poder público. Em sua fase financeira, o risco das atividades dos capitalistas é transferido ao Estado.

BERCOVICI e MASSONETTO exploram e dissecam este fenômeno, propondo que ocorreu a neutralização da Constituição Financeira no que batizaram de projeto de Constituição Dirigente Invertida. Segundo os autores, tenta-se atribuir um aspecto neutro e tecnicista ao conceito de austeridade fiscal, assegurando-se sua utilidade e eficácia na promoção do desenvolvimento econômico, o que reduz muito as possibilidades do desenvolvimento de políticas públicas. Essa ideia de um aspecto neutro da dívida pública seria falho, primeiro porque mesmo os defensores da austeridade fiscal tem revisto sua posição, incluindo economistas liberais como STIGLITZ4 ${ }^{4}$ conservadores como BLANCHARD (1990), BLANCHARD e PEROTTI (2002) e mesmo organismos internacionais como o FMI (2010).

Em segundo lugar, a imposição de uma agenda esterilizadora das políticas financeiras, como a aprovação da Emenda Constitucional do Teto de Gastos ${ }^{5}$, resultariam em uma verdadeira inversão de nosso projeto de Constituição (BERCOVICI; MASSONETTO, 2006). Se, como sugere a interpretação mais conservadora, os projetos de constituição dirigente poderiam ser entendidos como a imposição de um projeto às gerações futuras, seu contraponto, na forma de políticas extremadas de austeridade, poderia ser classificado como um exemplo de constituição dirigente invertida. Essa austeridade consolidaria o solapamento de direitos sociais e do projeto constitucional de sociedade, colocados em segundo plano frente as necessidades da burguesia de criação e recriação das condições para a acumulação de capital.

A posição pessimista dos autores parece derivar de uma certa descrença no projeto de constituição dirigente, com origem talvez na sua anunciada 'morte' (CANOTILHO, 2001, prefácio). A notícia da decretação da morte da constituição dirigente chegou ao Brasil trazida pelo professor Avelãs Nunes, resultando na antológica entrevista de Canotilho registrada por COUTINHO (2005), na obra

4 As manifestações de Stiglitz, apontando os riscos da austeridade fiscal, têm sido feitas principalmente em artigos de divulgação científica (jornais de grande circulação e revistas de interesse geral), e não em produções de cunho acadêmico, veja Stiglitz (2012; 2014a; 2014b)

${ }^{5}$ Emenda Constitucional no 95, de 15 de dezembro de 2016, que alterou o Ato das Disposições Constitucionais Transitórias para instituir o Novo Regime Fiscal. 
coletiva "Canotilho e a constituição dirigente". Na entrevista e nos debates o autor qualifica a asserção, ressalvando que "a constituição dirigente está morta se o dirigismo constitucional for entendido como normatismo constitucional revolucionário capaz de, por si só, operar transformações emancipatórias". O autor português, atento aos fenômenos do direito comunitário e dos novos blocos de poder, decreta que a morte da constituição dirigente se consumará se o texto constitucional "estiver vergado sobre si próprio e alheio aos processos de abertura do direito constitucional ao direito internacional e aos direitos supranacionais".

CANOTILHO, entretanto, renova o conceito de constituição dirigente, dando-lhe novo vigor, ao propor que "os textos constitucionais devem estabelecer as premissas materiais fundantes das políticas públicas num Estado e numa sociedade que se pretendem continuar a chamar de direito, democráticas e sociais".

\section{O Modelo NeOliberal e A CRítica do Welfare State}

O surgimento das liberdades civis e dos direitos políticos endereçaram, na ordem capitalista, a ascensão da burguesia e sua necessidade de calculabilidade para a condução dos seus negócios. Esta classe emergente temia, sobretudo, a ação do Estado. Assim, os direitos da liberdade visavam, especialmente, a manutenção do status quo, a abstenção do Estado e a redução de sua intervenção ao mínimo. A Constituição Belga de 1832 é um dos marcos nesta evolução, a mostrar o espírito da época. O documento transforma o dever de abstenção em direitos oponíveis ao Estado, retirando sua enunciação do preâmbulo constitucional e incorporando essas garantias no corpo constitucional, como direitos subjetivos e não mera norma programática (BONAVIDES, 2011, p. 229-231).

A política do laissez faire experimentou um refluxo no período das grandes guerras e, sobretudo, em função da Crise de 1929 e da depressão que se seguiu. Teóricos, sobretudo da economia, retomam o discurso do mercado como regulador das relações sociais no pós-guerra. Atacam as intervenções do Estado na economia, quer seja na forma dos programas sociais, da regulação e mesmo da direção na política econômica. FRIEDRICH HAYEK e MILTON FRIEDMAN estão entre os que propõe que as intervenções do Estado seriam inócuas, quando não prejudiciais. Não são poucos os exemplos que esses autores e seus seguidores apresentam como o que seriam limitações danosas ao livre arbítrio.

Para um exemplo, pais e alunos teriam sua liberdade de escolha tolhida pelo provimento de educação pelo Estado. Quando muito, um sistema de vouchers poderia ser utilizado, deixando às famílias as decisões sobre que educação prover a seus filhos (FRIEDMAN, 1955). Para outro exemplo, interferências nas relações trabalhistas seriam inúteis, pois a concessão de reajustes acima da inflação levaria ao imediato aumento de preços, já que os agentes seriam racionais e antecipariam os efeitos de tais aumentos. O conceito de expectativas racionais, em verdade, tornaria todas as políticas ativas do governo inúteis, já que os agentes antecipariam 
completamente seus efeitos e ajustariam suas expectativas ex ante ${ }^{6}$. Em todas as dimensões da vida social, a ação do Estado seria dispensável e pouco recomendada. O Estado deveria ser mínimo, para preservar a liberdade e não gerar ineficiências.

Essas propostas neoliberais são, na visão de outros pesquisadores ${ }^{7}$, incompatíveis com as evidências empíricas. O caráter cíclico das crises parece mostrar a natureza instável do capitalismo e sua pouca habilidade para garantir a paz social. No longo período de estabilidade que se seguiu à Segunda Guerra, o que se observou pelo mundo foram as experiências do Estado de Bem Estar Social e as políticas ativas do Estado.

A preocupação com os ciclos econômicos já estava na agenda de acadêmicos e formuladores de políticas públicas desde o início do século XX. Sinais dessa preocupação aparecem no estabelecimento de sistemas de contas nacionais e nos grandes esforços para entendimento dos business cycles em instituições como a Cowles Comission e a Econometric Society. A Crise de 1929 e o sucesso das políticas anticíclicas do New Deal de Roosevelt foram objeto de estudo e discussão, com grande produção teórica sobre o papel do Estado nos anos seguintes (BURNS; MitCHELL, 1946).

GUNNAR MYRDAL, que conheceu a experiência do New Deal de perto, propôs uma nova visão para os programas sociais, diferente da interpretação de cunho assistencialista até então associada a essas iniciativas. Programas sociais teriam a natureza de políticas sociais produtivas, regulamentações sociais voltadas a melhor organizar a produção. A característica desses programas não seria de mera despesa, mas de investimentos feitos para o aprimoramento econômico (ANDERSSON, 2004).

A construção mais influente e duradoura, entretanto, vem de JOHN KEYNES, refinada e estendida por seus seguidores. A capacidade de alcance do equilíbrio em um mercado perfeitamente competitivo, em verdade, não existiria. O nível da poupança agregada seria uma função da renda, expressa na propensão marginal de poupar e sujeita a um efeito multiplicador. Em sociedades mais desenvolvidas, onde o estoque de capital seria mais alto, seria difícil conseguir o retorno adequado para essa massa de recursos.

A redução de investimento nessa circunstância tem seu efeito ampliado pelo mesmo mecanismo dos multiplicadores de renda. A característica total do sistema é pró cíclica, e o nível dos investimentos depende muito mais da disposição dos empreendedores (ou, no dizer de KEYNES, dos espíritos animais) do que da poupança agregada. Soma-se ao fenômeno a não neutralidade da moeda - para os neoclássicos, o aumento de recursos na economia só teria efeitos inflacionários enquanto que para os keynesianos teria o efeito de reanimar a economia.

${ }^{6} \mathrm{O}$ conceito foi inicialmente discutido no contexto de políticas monetárias ativas (SARGENT; WALLACE, 1975).

7 As críticas vêm não apenas das correntes keynesianas e neo-keynesianas, mas também das abordagens da economia e das finanças comportamentais, da nova economia institucional e dos teóricos da economia sustentável, entre outros. 
Políticas ativas do Estado, a partir dessa perspectiva teórica, são necessárias para direcionar a economia ao pleno emprego e para evitar recessões prolongadas. Mecanismos de mercado não teriam o condão de levar à situações de justiça social, e a persecução do autointeresse pelos agentes, de forma não coordenada, não levaria à resultados socialmente ótimos. As abordagens keynesianas estiveram no bojo das políticas que conseguiram garantir por volta de 30 anos de crescimento e estabilidade econômica e social em todo o mundo. Para DRAIBE (1988), o Estado de bem-estar social tem característica mais ampla, com um cunho político, e não apenas social - não visa apenas a redução da desigualdade econômica, mas procura endereçar a segurança socioeconômica.

Em relação ao Brasil e América Latina, diversos autores apontam o quão tardia e insuficiente foi a ampliação da proteção social, com o marco da redução dessa desigualdade, no caso brasileiro, estabelecido pela constituição de 1988. KERSTENETZKY (2012) registra o que seria a expansão tardia do sistema de proteção social do Brasil, em linha com o que teria ocorrido na América Latina entre as décadas de 90 e princípio dos anos 2000. Os países da região guardariam semelhanças em relação ao grau de desigualdade, a baixa proporção do gasto social em relação à tributação e um passado de colonização ibérica. Segundo ARRETCHE (2018) a constituição de 1988 rompeu o paradigma da separação entre insiders e outsiders no Estado de bem estar brasileiro, onde apenas os inseridos no mercado de trabalho tinham direitos previdenciários e acesso a serviços do Estado - essa divisão e a exclusão, mesmo com a pouca capacidade de mobilização dos excluídos, levou a ampliação dos direitos sociais e da cobertura das políticas públicas.

\section{As Teorias de Médio Alcance}

As abordagens Marxista, Neoliberal e Neokeynesiana podem ser classificadas, em alguma medida, de exemplos das chamadas Grandes Teorias. Com inspiração que pode ser encontrada nos esforços de criação dos sistemas filosóficos de pensadores como Kant, Schelling e Hegel, as ciências sociais, desde o século XIX, observaram esforços de criação desses grandes esquemas teóricos, desde as tentativas de Comte e Spencer, passando pelos esforços de criação de uma teoria da ação social e da definição do funcionalismo estrutural de Talcott Parsons a partir dos anos 30 (MERTON, 1968), com influências de Weber e Durkheim, e chegando às discussões sobre o pluralismo, elitismo e outras formas de explicação da organização social sugeridas pela ciência política.

O desenvolvimento de um conceito de Teorias de Médio Alcance (ou MRT, na sigla originada da expressão em inglês), abordagem que viria a se mostrar de grande influência nos meios acadêmicos, especialmente na sociologia americana do pós-guerra, pode ser traçado em T. S. MARSHALL e, sobretudo, no trabalho desenvolvido por ROBERT MERTON ao longo de quase vinte anos. Em sua palestra inaugural na London School of Economics, em 1946, Marshall defende o recurso ao 
que chama de "degraus intermediários no desenvolvimento da teoria social" (MARSHALL, 1963, p. 03-24; MERTON, 1968, p. 51).

Essa ressalva à concentração excessiva no desenvolvimento de grandes teorias na pesquisa social ganha impulso com o debate entre Parsons e Merton, iniciado em 1948 com o artigo "A Posição da Teoria Social" publicada na American Sociological Review (PARSONS, 1948, p. 156-164). Nele o autor propõe que a teoria social deveria convergir para a produção de uma única grande estrutura conceitual (PARSONS, 1948, p. 157), com foco em uma explicação abrangente para a ação social conformada a uma teoria do tipo estrutural-funcionalista (PARSONS, 1948, p. 158). Embora Parsons sempre tenha recusado o rótulo de Grande Teoria para seu esquema conceitual, o pensador passou à história como o proponente do ambicioso programa de pesquisa estrutural-funcionalista.

Nesta mesma edição, Robert Merton apresenta o seu contraponto às proposições de Parsons (MERTON, 1948, p. 164-168). Reforça que a sugestão de Parsons seria a da criação de sistemas totais para o pensamento sociológico, com a proposição de uma única estrutura conceitual. Sua observação é a de que toda teoria sistematizada se constitui da acumulação de partes de teorias anteriores que sobreviveram ao escrutínio de décadas de pesquisa (MERTON, 1948, p. 165). Realizando a comparação com o desenvolvimento de ciências como a medicina e a química, sugere que essa busca por sistemas totais deve dar lugar a um conjunto de teorias mais limitadas, aplicáveis a determinados conjunto de dados. Nesta primeira discussão, entretanto, Merton ainda não utiliza a expressão Teorias de Médio Alcance (MRTs), conceito que será paulatinamente desenvolvido nos anos seguintes, em especial, MERTON (1957; 1963; 1968).

Essa proposição do uso de teorias mais adequadas ao teste empírico, entretanto, não significaria a redução da pesquisa social a um empirismo inócuo. Merton avalia que estado da produção teórica no pós-guerra possuía uma orientação geral à análise de dados, concentrada na sugestão de variáveis que deveriam ser de alguma forma levadas em conta na pesquisa social, sem que se fizessem suposições claras e testáveis sobre as relações entre essas variáveis. Em suas palavras, "temos muitos conceitos, mas poucas teorias confirmadas; muitos pontos de vista, mas poucos teoremas; muitas abordagens, mas poucas conclusões" (MERTON, 1948, p. 166).

Em 1968, Merton consolida suas ideias à respeito das Teorias de Médio Alcance no segundo capítulo de seu livro "Teoria Social e Estrutura Social". Em seu ensaio "Sobre as Teorias Social de Alcance Médio" ele sugere que essas teorias envolvem abstrações, mas são próximas o bastante dos dados observados a serem incorporados nas proposições a ponto de permitir seu teste empírico (MERTON, 1968, p. 39).

Por um lado, as MRTs não seriam simples derivações das chamadas Grandes Teorias, e por outro não seriam meras generalizações empíricas (Merton, 1968, p. 41). Em muitos casos seriam até compatíveis com diversas dessas grandes teorias exploramos mais adiante o conceito, mostrando como a chamada teoria do agente- 
principal pode ser utilizada tanto no contexto de uma análise marxista como de uma análise neoclássica.

O autor traça uma distinção entre teoria, um conjunto de pressupostos logicamente interrelacionados de onde hipóteses empíricas testáveis são derivadas, e generalização empírica, uma proposição isolada que resume relações uniformes observadas entre duas ou mais variáveis (MERTON, 1968, p. 66). As MRTs seriam essenciais para a acumulação do conhecimento, permitindo a consolidação de corpos cada vez maiores de sistemas de pensamento.

São vários os exemplos de MRTs explorados por MERTON em seu texto de 1968, essencialmente no campo da Sociologia. BOUDON retoma, em 1991, a discussão sobre as MRTs, com outros exemplos e reforçando o papel delas no desenvolvimento das Ciências Sociais (BOUDON, 1991, p. 519-522). De particular importância é a sua proposição para o que chama de aspectos negativos das Grandes Teorias. Para o autor, estas significariam uma desesperançada e quixotesca tentativa de determinar variáveis independentes de longo alcance que operariam em todos os processos sociais ${ }^{8}$, ou de determinar um aspecto essencial da teoria social (BOUDON, 1991, p. 519).

\section{O Direito e as Teorias de Médio Alcance}

O debate sobre as políticas públicas e as grandes teorias, como o funcionalismo e as teorias marxistas, encontra seus limites no último quarto do século passado. A definição e implementação de políticas públicas não parece depender única e exclusivamente das pressões dos diferentes grupos de interesse, como fariam supor as versões menos sofisticadas do pluralismo. Também não refletem exclusivamente os interesses daqueles grupos que estão no poder, a se adotar uma visão do elitismo simplificada. São todas questões importantes, mas podem levar facilmente a um determinismo que tornaria inútil a teorização a respeito de políticas públicas.

Reconhece-se que o aparato do Estado, seu mecanismo de gestão, é dotado sim de alguma autonomia, e sujeito a influências externas e internas. Em seu estudo, teóricos e formuladores de políticas se utilizam de ferramentas metodológicas e de teorias de médio alcance para explicar a realidade cheia de nuances que se apresenta na interação entre as políticas públicas e as formas de organização do Estado.

Essa análise não se dá unicamente no grande contexto das políticas públicas. Uma visão pormenorizada e a necessidade de estabelecer relações causais entre políticas e resultados requer o exame de competências, de questões alocativas e

\footnotetext{
8 A menção de BOUDON a variáveis independentes segue sua longa produção teórica sobre mecanismos e sobre processos geradores de dados (BOUDON, 1979; 1998). Essas discussões se encaixam em uma reflexão sobre causalidade e individualismo metodológico, importantes para o entendimento da pesquisa empírica em direito e políticas públicas mas fora do escopo do presente trabalho. Desenvolvemos essas ideias em RIBEIRO (2019a; 2019b).
} 
distributivas, da participação dos diversos grupos de interesse, e de formas de coordenação federativa e entre agentes públicos e privados, entre outros aspectos. O que se observa é que esse tipo de análise pressupõe uma abordagem de Direito e Políticas Públicas, e a produção de hipóteses testáveis demanda a migração das grandes teorias para as MRTs. Após este trajeto, a partir de uma profunda base empírica e teórica, se construirão esquemas explicativos mais amplos.

São também muitos os exemplos, neste dossiê, de análises feitas a partir da referida ideia do Direito como building block das políticas públicas. Na área da educação, TOLEDO examina as políticas de valorização de professores da educação básica, a ser feita através do estabelecimento de um plano de carreira nacional e da fixação de um piso salarial. Ainda em relação à educação básica, JORGE (2019), examina como a regulação para cursos de formação de professores da educação básica sofre com a faltas de consistência sistêmica de suas normas. DUARTE nota como questões relativas ao federalismo cooperativo e conflitos de natureza distributiva estão no bojo das dificuldades de sistematização do Sistema Nacional de Ensino (SNE). O federalismo cooperativo também é apontado como elemento essencial da abordagem direito e políticas públicas no estudo de vias urbanas e sua função social (HADDAD, 2019), assim como o conflito distributivo, como problema central no enfrentamento das questões relativas ao saneamento básico (VALENTE, 2019).

A conjugação de MRTs com o estabelecimento de relações de causalidade através da verificação empírica de sua validade por meio de hipóteses testáveis encontra já algum eco não apenas na avaliação de políticas públicas, mas também em questões jurídicas e da ciência política mais amplas, por exemplo examinando cortes supremas e outras instâncias da Justiça.

Neste sentido, TAYLOR (2006) parte da teoria de TSEBELIS (1995; 2002), dos chamados veto players, para testar se a estrutura das cortes constitucionais ofereceria uma via que seria especialmente vantajosa para alguns grupos sociais em sua busca pelo bloqueio de políticas públicas que alterariam o status quo - ou seja, o autor parte de uma típica teoria de médio alcance para testar a possibilidade de que o STF serviria como policy venue para determinados grupos sociais ${ }^{9}$.

Para outro exemplo, vejam-se as análises de RIBEIRO sobre a arbitragem (RIBEIRO, 2008) e a justiça especializada (RIBEIRO, 2007b). O autor parte, nos dois casos, de uma perspectiva de individualismo metodológico no contexto da Nova Economia Institucional. A relação entre os ocupantes de cargos de direção empresas de capital aberto e os acionistas a quem eles servem é de delegação de poderes, através da eleição em assembleias de acionistas. Este tipo de relação tem sido examinado por economistas e cientistas políticos através da chamada agency

\footnotetext{
${ }^{9}$ O teste de Taylor, entretanto, faz essa análise partindo do exame do resultado de ações judiciais, sem considerar a possibilidade do chamado viés de seleção. Veja-se, a respeito da aplicação do viés de seleção aos litígios judiciais, PRIEST e KLEIN (1984) e, no Brasil, a contribuição pioneira de RIBEIRO (2007a), veja também NUNES et al (2015).
} 
theory (HolmStrom; Milgrom, 1987) ${ }^{10}$. Quem recebe a delegação é chamado de agente, e exerce um mandato outorgado pelo chamado principal - no caso da gestão de companhias abertas, o acionista.

$\mathrm{O}$ que o modelo examina são as consequências dessa relação de delegação. $\mathrm{O}$ agente, ao lidar diretamente com a tarefa, torna-se mais bem informado que o principal. Seus interesses podem ser divergentes dos de seus constituintes, e o nível de esforço que realiza - por exemplo, seguindo um comportamento ético ou empreendendo seus melhores esforços pelo bem da sociedade - pode não ser diretamente observável. Acrescenta ao problema que o resultado nem sempre refletirá os esforços ou o bom comportamento ético e diligente do agente.

Nesse contexto, o agente pode ter um comportamento que vai contra os interesses de seu constituinte. Pode aprovar políticas prejudiciais ao acionista, mas que propiciam oportunidades de ganho pessoal, ou pode se tornar leniente, já que os resultados do comportamento diligente não são sempre observáveis. Com base na Teoria do Agente-Principal, RIBEIRO estabelece hipóteses testáveis em relação aos resultados da arbitragem e da especialização da justiça em matéria empresarial (RIBEIRO, 2008; 2007b).

Uma abordagem semelhante, partindo da teoria de agente e principal, pode ser encontrada no trabalho de PRZEWORSKI (1998), em uma perspectiva neo marxista do exame da estrutura do Estado. Como adiantava Merton, as MRTs podem, por vezes, estar ligadas a mais de uma das tradições das grandes teorias.

Outras perspectivas metodológicas acabam por refinar as relações que pesquisadores tentam estabelecer entre a atuação estatal e políticas públicas. HERBERT SIMON coloca um óbice ao postulado neoclássico de racionalidade ilimitada dos agentes, o que está na origem das abordagens baseadas em teorias da informação, em especial, JOSEPH STIGLITZ e WEISS (1981). Ainda colocando críticas aos pressupostos neoclássicos, temos correntes comportamentais, questionando o pressuposto de racionalidade dos agentes, por todos, KAHNEMAN e TVERSKY (1979) e TVERSKY e KAHNEMAN (1974). Entre os marxistas analíticos, são várias as abordagens metodológicas, incluindo a teoria dos jogos e outras com viés de individualismo metodológico.

Pode-se ainda destacar, entre as teorias de médio alcance, as várias vertentes do neoinstitucionalismo (especialmente o de base econômica, de DOUGLASS NORTH, e o de sociologia histórica). Essas abordagens se propõem a olhar o efeito das instituições, com variadas definições, sobre os resultados da ação do Estado e da sociedade. Não são teorias que procuram dar uma explicação de fundo a todos os fenômenos sociais, mas procuram em verdade qualificar a discussão, propondo um melhor ajuste entre as observações empíricas e seus contextos históricos e sociais -

${ }^{10}$ A chamada agency theory pode, em alguns casos, ser melhor entendida como um dispositivo empírico do que como uma MRT. Essa é a leitura que pode ser feita, por exemplo, a partir de MCCUBBINS, NOLL e WEINGAST (1987). 
as análises de RIBEIRO (2007a; 2007b; 2008) se dão neste contexto do institucionalismo menos abrangente de NORTH.

A possibilidade de partir de pesquisas com foco em MRTs e abordagens empíricas, com vistas ao estabelecimento de esquemas teóricos mais amplos, poderia servir como uma retomada aos estudos, no Brasil, da chamada Teoria do Estado. Como aponta BUCCI (2018), à teoria do estado caberia o papel de "compreensão sistemática de informações e conceitos presentes em pesquisas de diversas matizes, dispersas entre dados empíricos e análise de fenômenos parciais".

Essa necessidade de aproximar os campos empíricos e teóricos na abordagem Direito e Políticas Públicas requer, novamente, o refinamento do aparato metodológico e a busca renovada da interdisciplinaridade, sobretudo no ensino do Direito $^{11}$. Dispositivos empíricos como o Quadro de Análise de Políticas Públicas e o Quadro de Problemas em Políticas Públicas contribuem com essa aproximação e dão as condições para testes empíricos mais rigorosos e mais alinhados com testes de hipóteses e o estabelecimento de relações causais. ${ }^{12}$

\section{CONCLUSÕES}

As concepções de Estado têm uma influência grande sobre a definição e implementação de políticas públicas. São muitas as Teorias do Estado aplicáveis à discussão, e suas consequências são as mais diversas possíveis.

Para um derradeiro exemplo, examine-se a questão da participação social na definição de políticas públicas. Uma abordagem com lastro nas teorias democráticas vai se preocupar não apenas com a possibilidade de participação formal, mas também com esforços ativos de inclusão - o objetivo é conseguir, nesse contexto, a participação de grupos normalmente excluídos do debate e pouco representados nas políticas, sem que exista o risco de retirada de seus direitos por maiorias eventuais.

Notável foi, partindo dessa orientação, o esforço nos últimos anos para aumentar a participação da sociedade, através do uso intensivo das conferências nacionais de políticas públicas, da ampliação da atuação de conselhos de políticas públicas e mesmo a formulação de um Plano Nacional de Participação Social (PNPS) ${ }^{13}$, entre outras medidas. A mudança do grupo controlando o governo, que opera com um lógica mais alinhada com uma visão neoliberal, têm levado ao abandono dessa política de aumento da participação social.

Simbólica dessa inflexão é, por exemplo, a mudança na composição do Fórum Nacional da Educação (FNE), com a exclusão de membros, o adiamento da

\footnotetext{
${ }^{11}$ Em relação aos desafios no ensino dentro de uma abordagem de Direito e Políticas Públicas, sobretudo em relação a interdisciplinaridade, veja-se neste dossiê BRUNET e também RIZZI e BAMBINI.

${ }^{12}$ Veja neste dossiê, sobre esses dispositivos empíricos, RUIZ e BUCCI, MALHEIROS, CHILVARQUER, e também WERNER.

${ }^{13}$ Decreto no 8.243, de 23 de maio de 2014, revogado pelo Decreto no 9.759, de 11 de abril de 2019.
} 
Conferência Nacional de Educação (CNE) e, também neste sentido, da Conferência Nacional das Cidades (CNC), além da redução do seu escopo de deliberação. Em portaria editada em agosto de 2017, o então ministro da educação Mendonça Filho fez substanciais alterações na composição do FNE e na organização da Conferência Nacional de Educação ${ }^{14}$, excluindo representantes de 14 entidades da sociedade civil e colocando em seu lugar um número maior de órgãos ligados diretamente ao governo. Foi ainda estabelecida a concorrência por vagas para os representantes que foram mantidos, e também foi transferida a organização do evento, retirada do FNE e atribuída agora à Secretaria Executiva do ministério. Por fim, foi feito o adiamento da realização da CNE para, no mínimo, o segundo semestre de $2018^{15}$.

O debate sobre as concepções de Estado, dessa forma, não é mera questão teórica, envolvendo aspectos de fundo das discussões sobre a definição, implementação e avaliação de políticas públicas, com amplo interesse para seus formuladores. A tentativa de explicação dessas clivagens com base nas chamadas grandes teorias não permite seu teste empírico. No mais das vezes, a proposição de grandes teorias deriva em explicações tautológicas e não testáveis em matéria de políticas públicas.

Em especial, uma abordagem positiva das políticas públicas exige o exame de aspectos como competências, questões de execução orçamentária, participação popular, incentivos e outras que demandam um olhar atento sobre os instrumentos jurídicos utilizados no planejamento, implementação e avaliação de políticas públicas. O foco, neste exame notadamente empírico, se dá sobre os aspectos jurídicos, demandando a assim chamada abordagem Direito e Políticas Públicas. Essa abordagem, entretanto, não á suficiente. Proposições testáveis demandam teorias menos ambiciosas, mais próximas dos dados, de forma a tornar factível a proposição de hipóteses testáveis. O estado da arte na pesquisa em Ciências Sociais mostra, em nosso entendimento, essa virada empírica, fundada na construção das grandes teorias a partir das MRTs e de seu teste empírico.

O próprio esforço do desenho de uma abordagem de pesquisa do grupo Estado, Direito e Políticas Públicas, que resultou neste dossiê, parte de uma visão comum do que seria este estado da arte. Como costumamos apontar em diversas ocasiões, BUCCI (2013, p. 291-292) adianta muitos desses aspectos, e é com algumas citações deste trabalho que concluímos este artigo.

Posto o fenômeno governamental no nível mais próximo de observação, o microinstitucional, pode-se analisar o papel das subjetividades, os indivíduos, os grupos, seus interesses atomizados ou agregados. A

${ }^{14}$ Portaria no 1.017 de 22 de agosto de 2017, publicada pelo Ministério da Educação no DOU do dia 23 de agosto de 2017, na Seção 2, p. 9 - o evento, ao final, ocorreu de 21 a 23 de novembro de 2018. ${ }^{15} \mathrm{O}$ adiamento foi feito através do Decreto de 28 de abril de 2017 da Presidência da República, sem número, que apresenta nova data e cronograma para a 3ª Conferência Nacional de Educação (Conae). 
categoria epistemológica processo, com sua carga de significados tanto para o campo do direito [...] como para a ciência política e demais ciências sociais, passa a ser o referencial para a compreensão de como se formam as decisões governamentais no nível microinstitucional e como são executadas, e quais foram as formas que organizaram o enfretamento dos conflitos e suas soluções no interior do aparelho do Estado.

Num nível maior de distanciamento, podemos ver as formas de organização de nível médio (middle range), ou o plano mesoinstitucional da ação governamental. Neste plano, toma-se como referência a categoria das instituições, considerando a larga tradição dessa figura no direito [...] e seu enraizamento na ciência política, para compreender a dimensão objetiva da ação governamental, expressa nos arranjos institucionais, que transcendem a abrangência individual, as iniciativas dos governantes e demais partícipes da ação, para assumir significados coletivos.

Após dar conta da necessidade dessa abordagem micro e meso institucional, que encontra perfeita ressonância na ideia da adoção das Teorias de Médio Alcance, BUCCI (2013, p. 295-298) sugere uma abordagem que, a nosso ver, antecipa a importância do olhar empírico dedutivo-indutivo, calcado no individualismo metodológico para o estabelecimento de relações causais:

A abordagem dedutiva, do geral para o particular, é mais apropriada para a construção dos modelos analíticos, nos quais se organiza a compreensão de como se formam e atuam as políticas públicas. A abordagem indutiva consubstancia-se em inferências, a partir de casos concretos e particulares, até as hipóteses gerais, formuladas nos modelos. [...]

O que não é usual é a análise sistemática apoiada num método de isolamento de variáveis - para nosso objeto de interesse, jurídicas, ou juridicamente disciplinadas - que apontem razões de sucesso ou insucesso de determinada ação governamental. Esse procedimento é adotado, com certeza, mas de forma individual e pouco apropriada à extração de resultados de maior alcance.

O desafio é criar o roteiro ou chave de análise, que permita as comparações entre casos, de modo a proporcionar o acúmulo que viabilizará os estudos de segundo nível, isto é, com base na reflexão sobre as descobertas empíricas a partir da comparação de dados e do isolamento de variáveis.

BUCCI aponta a necessidade de se fazer comparações estruturadas, partindo de visões compartilhadas entre pesquisadores, ou seja, a necessidade de um vocabulário comum e cânones de análise. Por fim, aponta essa estrutura de estabelecimento de relações causais em outras ciências sociais aplicadas, sobretudo 
na aplicação de abordagens quantitativas como a econometria, com o isolamento de variáveis e os testes que procuram estabelecer correlações ${ }^{16}$.

A adoção de uma visão calcada em elementos do Direito e o exame empírico a partir de Teorias de Médio Alcance apresenta, em nossa opinião, um último desafio, que é o de avançar para abordagens qualitativas e quantitativas hábeis a fazer o isolamento de variáveis a e possibilidade de generalizações. Como aponta BUCCI (2013, p. 298), este esforço é o que foi feito, por exemplo, na Medicina, que depois de acumular um grande corpo de evidências empíricas na forma de estudos de caso, passou a sua sistematização, como forma de testar hipóteses generalizáveis e, depois construir teorias de alcance maior. Esse é o desafio que se apresenta aos estudiosos de Direito e Políticas Públicas.

\section{REFERÊNCIAS}

ANDERSSON, Jenny, A productive social citizenship? Reflections on the concept of productive social policies in the european tradition, In: MAGNUSSUN, Lars; STRATH, Bo (eds.) A European Social Citizenship? Preconditions for Future Policies from a Historical Perspective. Bruxelas: P.I.E. Peter Lang, 2004.

ARRETCHE, Marta. Democracia e redução da desigualdade econômica no Brasil: a inclusão dos outsiders. Revista Brasileira de Ciências Sociais, v. 33, n. 96, p. 1-23, 2018.

BECKER, Howard. Sociological work: method and substance, London: Transaction Publishars, 1970.

BERCOVICI, Gilberto. As Possibilidades de Uma Teoria do Estado. Rev. Faculdade Direito Universidade Federal Minas Gerais, v. 49, p. 81-100, 2006.

BERCOVICI, Gilberto; MASSONETTO, Luis Fernando. A constituição dirigente invertida: a blindagem da constituição financeira e a agonia da constituição econômica. Boletim de Ciências Econômicas, v. XLIX, p. 57-77, 2006.

\footnotetext{
${ }^{16}$ A autora sugere que abordagens como a econometria e, adicionaríamos, a jurimetria, encontraria limites onde os indicadores não fossem sempre quantificáveis. Particularmente, discordamos dessa impossibilidade, já que muito da literatura estatística e econométrica já lida com aspectos da inferência em pesquisas qualitativas. Para uma argumentação detalhada e profunda a esse respeito, veja-se BECKER (1970), capítulos 1 a 3.
} 
BLANCHARD, Olivier J. Suggestions for a New Set of Fiscal Indicators. OECD 46 Economics Department Working Paper No. 79. Paris: Organization for Economic Cooperation and Development, 1990.

BLANCHARD, Olivier J.; PEROTTI, Roberto. An Empirical Characterization of the Dynamic Effects of Changes in Government Spending and Taxes on Output. Quarterly Journal of Economics, v. 107, p. 1329-1368, 2002.

BONAVIDES, Paulo. Curso de Direito Constitucional, 26. ed. São Paulo: Malheiros, 2011.

BOUDON, Raymond. Generating models as a research strategy. In: MERTON, Robert (ed.) Qualitative and Quantitative Social Research. Nova York: Free Press, 1979.

BOUDON, Raymond. What Middle-Range Theories Are. Contemporary Sociology, v. 20, n. 4, 1991, p. 519-22.

BOUDON, Raymond. Social mechanisms without black boxes. In: HEDSTROM, Peter; SWEDBERG, Richard (eds.) Social mechanisms: An analytical approach to social theory. Cambridge University Press, 1998.

BRUNET, Emiliano R. Sobre a abordagem acadêmica de políticas públicas em um curso de graduação em direito: contribuição para um programa. Revista Estudos Institucionais, v. 5, n. 3, 2019.

BUCCI, Maria P. D. Políticas Públicas e Direito Administrativo. Revista de Informação Legislativa, v. 34, n. 133, jan./mar., 1997.

BUCCI, Maria P. D. Fundamentos para uma Teoria Jurídica das Políticas Públicas. São Paulo: Saraiva, 2013.

BUCCI, Maria P. D. Teoria do Estado: Sentidos Contemporâneos. São Paulo: Saraiva, 2018.

BUCCI, Maria Paula Dallari. Método e aplicações da abordagem Direito e Políticas Públicas (DPP). Revista Estudos Institucionais, v. 5, n. 3, 2019.

BURNS, Arthur F.; MITCHELL, Wesley C. Measuring business cycles. 1946. 
CANOTILHO, J.J. Constituição dirigente e vinculação do legislador. 2. ed. Coimbra: Coimbra Editora, 2001.

CHILVARQUER, Marcelo. Aplicando o quadro de referência para análise jurídica de políticas públicas: a implementação do Programa Minha Casa, Minha Faixa 1 no Município de São Paulo. Revista Estudos Institucionais, v. 5, n. 3, 2019.

COMPARATO, Fábio Konder. Ensaio sobre o Juízo de constitucionalidade das políticas públicas. Revista de Informação Legislativa, v. 35, n. 138, p. 39-48, 1998.

DOMHOFF, G. William. The powers that be: Processes of ruling-class domination in America. New York: Vintage Books, 1979.

DRAIBE, Sonia. O Welfare State no Brasil: características e perspectivas. São Paulo: Universidade Estadual de Campinas, 1988.

DUARTE, Clarice Seixas. Os entraves à institucionalização do SNE: uma análise a partir da metodologia de pesquisa jurídica em políticas públicas. Revista Estudos Institucionais, v. 5, n. 3, 2019.

FRIEDMAN, Milton. The role of government in education. In: SOLO, R. A. (ed.). Economics and the public interest. New Brunswick, NJ: Rutgers University Press, 1955.

FRIEDMAN, Milton. There's No Such Thing as a Free Lunch. LaSalle, IL: Open Court, 1975.

FUNDO MONETÁRIO INTERNACIONAL. Will It Hurt? Macroeconomic Effects of Fiscal Consolidation. Economic Outlook, 2010.

GRAU, Eros Roberto. Resenha do prefácio da 2a edição. In: COUTINHO, Jacinto N. M. (org.). Canotilho e a constituição dirigente. Rio de Janeiro: Renovar, 2005.

GRAU, Eros Roberto. A ordem econômica na Constituição de 1988: interpretação e crítica. 14. ed. São Paulo: Malheiros, 2010.

GRAU, Eros Roberto. O Direito posto e o Direito pressuposto. 8. ed. São Paulo: Malheiros, 2011. 
GILENS, Martin; PAGE, Benjamin I. Testing theories of American politics: Elites, interest groups, and average citizens. Perspectives on politics, v. 12, n. 3, 2014, p. 564-581.

HACKER, Jacob S.; PIERSON, Paul. After the "master theory": Downs, Schattschneider, and the rebirth of policy-focused analysis. Perspectives on Politics, v. 12, n. 3, 2014, p. 643-662.

HADDAD, Frederico. A pertinência da abordagem de Direito e Políticas Públicas ao estudo da política urbana no Brasil: o exemplo da pesquisa jurídica sobre as vias urbanas e sua função social. Revista Estudos Institucionais, v. 5, n. 3, 2019.

HOLMSTROM, Bengt; MILGROM, Paul. Aggregation and linearity in the provision of intertemporal incentives. Econometrica: Journal of the Econometric Society, p. 303-328, 1987.

JORGE, Ighor Rafael de. Processo de elaboração normativa e políticas públicas: a visão jurídico-institucional da política de formação de professores da educação básica. Revista Estudos Institucionais, v. 5, n. 3, 2019.

KAHNEMAN, Daniel; TVERSKY, Amos. Prospect theory: An analysis of decision under risk. Econometrica, v. 47, n. 2, p. 363-391, 1979.

KERSTENETZKY, Celia. O estado do bem-estar social na era da razão. Elsevier Brasil, 2012.

LENHARDT, Gero; OFFE, Claus. Social policy and the theory of the state. In: KEANE, John (ed.). Contradictions of welfare state (contemporary politics series). Londres: Hutchinson \& Co, 1984.

LOEWENSTEIN, Karl. Political power and the governmental process. Chicago: The University of Chicago Press, 1965.

MALHEIROS, Rafael Taranto; DUARTE, Clarice Seixas. A dimensão jurídicoinstitucional da política pública da regularização fundiária urbana de interesse social e a busca de sua efetividade. Revista Estudos Institucionais, v. 5, n. 3, 2019.

MAZZUCATO, Mariana. The entrepreneurial state: Debunking public vs. private sector myths. Anthem Press, 2015. 
MCCUBBINS, Mathew D.; NOLL, Roger G.; WEINGAST, Barry R. Administrative procedures as instruments of political control. JL Econ. \& Org., v. 3, 1987.

MERTON, Robert K. Discussion of Talcott Parsons "The position of sociological theory". American Sociological Review, v. 13, 1948.

MERTON, Robert K. Social theory and social structure. Nova Iorque: Free Press, 1968.

NUNES, M. Ribeiro, I., ROQUIM, P., TRECENTI, J. The Sheriff of Nottingham Hypothesis: A Tribute to Theodore Eisenberg. Journal of Institutional and Theoretical Economics (JITE), v. 171, n. 1, 2015, p. 122-140.

OFFE, Claus. The theory of the capitalist state and the problem of policy formation. In: LINDENBERG et al. (orgs.) Stress and contradiction in modern capitalism. Toronto: Lexington, 1975.

PARSONS, Talcott. The position of sociological theory. American Sociological Review, v. 13, 1948, p. 156-164.

POUlANTZAS, Nicos. Political Power and Social Classes. Tradução Timothy O'Hagan. Londres: Verso, 1978.

PRZEWORSKI, Adam. Sobre o desenho do Estado: uma perspectiva agent $\mathrm{x}$ principal. In: PEREIRA, Luiz Carlos Bresser; SPINK, Peter Kevin (orgs.). Reforma do Estado e administração pública gerencial. São Paulo: Fundação Getúlio Vargas Editora, 1998.

PRIEST, George L.; KLEIN, Benjamin. The selection of disputes for litigation. Journal of Legal Studies, v. 13, n. 1, 1984, p. 01-55.

RIBEIRO, Ivan C. Robin Hood vs. King John: Como os Juízes Locais Decidem Casos no Brasil? Brasília: Ipea, Prêmio IPEA 40 anos, 2007a.

RIBEIRO, Ivan C. CVM e Judiciário: O efeito da incerteza jurídica nos investimentos em ações e a Justiça Especializada. Revista Direito GV, v. 5, p. 35-56, 2007b.

RIBEIRO, Ivan C. Arbitragem, Risco Legal e o Novo Mercado da Bovespa. Revista de Arbitragem e Mediação, v. 10, 2008, p.110-142. 
RIBEIRO, Ivan C. O Individualismo Metodológico na Pesquisa em Direito e Políticas Públicas. Manuscrito em progresso, 2019a.

RIBEIRO, Ivan C. Causalidade e Políticas Públicas. Manuscrito em progresso, 2019b.

RIZZI, Ester Gammardella; BAMBINI, Gustavo. A tarefa de ensinar direito no campo das políticas públicas. Revista Estudos Institucionais, v. 5, n. 3, 2019.

RUIZ, Isabela; BUCCI, Maria Paula Dallari. Quadro de problemas de políticas públicas: uma ferramenta para análise jurídico-institucional. Revista Estudos Institucionais, v. 5, n. 3, 2019.

SARGENT, Thomas J.; WALLACE, Neil. Rational expectations, the optimal monetary instrument, and the optimal money supply rule. Journal of political economy, v. 83, n. 2, 1975, p. 241-254.

SIMON, Herbert A. Bounded rationality and organizational learning. Organization science, v. 2, n. 1, 1991, p. 125-134.

SOUZA, Celina. A nova gestão pública. In: Cadernos da Fundação Luís Eduardo Magalhães. Gestão pública: desafios e perspectivas, 2001.

SOUZA, Celina. O Estado da Arte da Pesquisa em Políticas Públicas. In: HOCHMAN, Gilberto; ARRETCHE, Marta; MARQUES, Eduardo (eds.). Políticas públicas no Brasil. Rio de Janeiro: Fiocruz, 2007.

SOUZA, Matheus Silveira de; BUCCI, Maria Paula Dallari. O estado da arte da abordagem direito e políticas públicas em âmbito internacional: primeiras aproximações. Revista Estudos Institucionais, v. 5, n. 3, 2019.

STIGLITZ, Joseph E.; WEISS, Andrew. Credit rationing in markets with imperfect information. American Economic Review, v. 71, n. 3, 1981, p. 393-410.

STIGLITZ, Joseph. After austerity. Project Syndicate, v. 7, 2012.

STIGLITZ, Joseph. Austerity has been an utter disaster for the eurozone. The Guardian, 2014a.

STIGLITZ, Joseph. Europe's Austerity Zombies. Project Syndicate, v. 26, 2014b. 
TAYLOR, Matthew M. Veto and voice in the courts: policy implications of institutional design in the Brazilian judiciary. Comparative Politics, 2006, p. 337355.

TOLEDO, Carlos José Teixeira de. O neoinstitucionalismo histórico como método de análise jurídica de políticas públicas: o estudo da trajetória da política de carreira docente. Revista Estudos Institucionais, v. 5, n. 3, 2019.

TSEBELIS, George. Decision making in political systems: Veto players in presidentialism, parliamentarism, multicameralism and multipartyism. British journal of political science, v. 25, n. 3, 1995, p. 289-325.

TSEBELIS, George et al. Veto players: How political institutions work. Princeton University Press, 2002.

TVERSKY, Amos; KAHNEMAN, Daniel. Judgment under uncertainty: Heuristics and biases. Science, v. 185, n. 4157, 1974, p. 1124-1131.

VALENTE, Sérgio Ruy David Polimeno. Direito e políticas públicas: uma visão jurídico-institucional sobre o caso do saneamento básico no Brasil. Revista Estudos Institucionais, v. 5, n. 3, 2019.

WAGNER, Peter. Public Policy, Social Science, and the State: An Historical Perspective. In: FISCHER, Frank; MILLER, Gerald (eds.). Handbook of Public Policy Analysis: Theory, Politics, and Methods. New York: Routledge, 2007.

WERNER, Patricia Ulson Pizarro. A abordagem Direito e Políticas Públicas como ferramenta de aprimoramento das Instituições Jurídicas: qualidade organizacional, sistematização de dados e aperfeiçoamento das relações interinstitucionais. Revista Estudos Institucionais, v. 5, n. 3, 2019. 